\title{
Preservice Physics Teachers' Development of Physics Identities: the Role of Multiple Representations
}

\author{
Nuril Munfaridah $^{1,2}$ (D) Lucy Avraamidou $^{1}$ (D) Martin Goedhart $^{1}$ (D)
}

Accepted: 25 July 2021 / Published online: 1 September 2021

(c) The Author(s) 2021

\begin{abstract}
Identity-based research in physics education has been receiving increased attention in the past few years given the potential of identity in producing novel insights into the ways' students engage in physics. In this study, we examined the development of preservice physics teachers' physics identity through a specific instructional practice: a specially designed course incorporating the use of the multiple representations. Although specific programs and instructional practices have been found to influence the development of physics identity, there is no clear evidence about the kinds of instructional practices that might support its development. To examine the influence of multiple representations on each component of physics identity, we designed and implemented a physics course that used a multiple representation (MR)-based instructional approach with a group of 61 preservice physics teachers at a public university in Indonesia. Data were collected with a pre- and post-questionnaire on physics identity, a conceptual understanding test, and a post-test that examined differences between identity components before and after the course, conceptual understandings, as well as the participants' views about the use of the MR-based instructional approach. The findings revealed a significant improvement of two components of physics identity, namely, competence and interest, and point to the potential of MR-based instruction in physics courses.
\end{abstract}

Keywords Physics identity $\cdot$ Physics teacher education $\cdot$ Multiple representations $\cdot$ Physics education

\section{Introduction}

Identity-based research in science education and physics education in particular has been receiving increased attention in the past few years given the potential of identity in producing novel insights into the ways students engage in physics (Berge et al., 2019; Close et al.,

Nuril Munfaridah

n.munfaridah@rug.nl

1 Institute for Science Education and Communication, University of Groningen, Nijenborgh 7, 9747 AG Groningen, Netherlands

2 Department of Physics, Faculty of Mathematics and Natural Sciences, Universitas Negeri Malang, Jl. Semarang No.5, Malang 65145, Indonesia 
2016; Danielsson, 2014; Hazari et al., 2010, 2015; Irving \& Sayre, 2013; Wulff et al., 2011). As a construct, identity has been used in science education research to refer to how people see themselves and how they are seen or recognized by others (Avraamidou, 2014). As Gosling (2017) argued, the construct of identity allows us to understand not only the difficulties that students face with the content but also how students view themselves in comparison to the modes of behavior and learning that is expected in the physics classroom.

Physics identity is a specific disciplinary identity that is used to define how people come to see themselves as a physics person and are seen by others as a physics person in the process of developing this identity (Wulff et al., 2011). Physics identity has been defined as consisting of four main components: interest, competence, performance, and recognition (Hazari et al., 2010). As we will discuss in the next section, a review of the identity-based literature shows that a few researchers have examined the factors influencing identity development (Hazari et al., 2010; Irving \& Sayre, 2013, 2015; Wang et al. 2020), how teachers' and students' positioning in the classroom affects physics identity development (Berge et al., 2019; Hazari et al., 2015; Jackson \& Seiler, 2017), and the kinds of activities that support identity development in out-of-school contexts (Close et al., 2016; Lock et al., 2019; Wulff et al., 2011). What is currently missing from the existing knowledge base is an understanding of the kinds of classroom practices that may contribute to the development of physics identity (Hazari et al., 2010). This is precisely what the study reported in this manuscript aims to do through an examination of the use of multiple representations in physics instruction and its impact on each of the components of physics identity.

As defined by Treagust et al. (2018), the term multiple representation (MR) refers to the "combination of different modes of representation such as analogies, diagrams, graphs, cartoons, formulas, text, simulations, and gestures to communicate scientific concepts in scientific discourse and science learning" (p. 122). A few researchers reported that the use of this approach has benefits for increasing students' problem-solving skills (Kohl \& Finkelstein, 2006; Sutopo, \& Waldrip, 2014), and students' conceptual understanding (McPadden $\&$ Brewe, 2017). We contend that this approach might also contribute to the self-view as "a physics person," which is central to physics identity (Hazari et al., 2010). This assumption is rooted within existing literature that shows that being a "good physics student" translates into being a "good physics problem solver" (Danielsson, 2014), which includes the ability to use MR (De Cock, 2012).

Hence, by examining if an MR-based instructional approach influences the development of the components of physics identity, we aim to contribute to an existing knowledge gap about the kinds of instructional practices that might contribute to the development of physics identity. We maintain that the use of an MR-based instructional approach to physics teaching might contribute to the development of specific components of physics identity, because (a) MR might be used for the presentation of real-world problems in ways that enhance student interest and engagement (Ainsworth, 1999), (b) MR have the potential to enhance students' conceptual understanding and problem-solving skills (Kohl \& Finkelstein, 2017; Sutopo, \& Waldrip, 2014) which is directly related to both their competence and performance, and (c) the use of questions that involve graphs and tables correlates with interest and self-recognition (Lock et al., 2015). 


\section{Theoretical and Empirical Underpinnings}

As reported elsewhere, science identity has been conceptualized and used in science education research in different ways and for different research purposes (Avraamidou, 2014). One of the most prominent models that has been used in science education research is the model developed by Carlone and Johnson (2007), which includes the following three components: (a) competence, which refers to knowledge and understanding of science content; (b) performance, which refers to the social performances of relevant scientific practices; and (c) recognition, which refers to recognizing oneself and recognized by others as a science person. Grounded within this identity model, Hazari et al. (2010) developed a disciplinary-based identity framework that focuses on physics. This model includes the addition of the component of "interest." The framework also deviates from Carlone and Johnson's model in terms of defining the three other components of identity. Instead of measuring actual competence, recognition, and performance, Hazari and et al.'s framework measures belief in competence, recognition, and performance. While such a conceptualization has advantages in terms of research feasibility, especially with big data sets in qualitative research (e.g., difficulty to ethnographically observe how individuals perform scientific practices or how they are actually recognized by others), it also has certain limitations found at the dichotomy between what is actual and what is perceived to be true.

For the purpose of this study, we use a combined framework of physics identity based on Carlone and Johnson's model and Hazari's framework. In the context of our study, physics identity is used to refer to four components that support the conceptualization of an individual as a physics person as follows: competence, performance, interest, and recognition. In what follows, we explain and justify our decisions. First, given our interest in physics, we considered Hazari's framework to be more appropriate given its disciplinarily nature. In addition, given that the participants in our study are preservice teachers and not scientists whose interest is granted, like in Carlone and Johnson's study, we include the interest component. In order to address the limitation of belief in competence instead of actual competence, in this study, we use actual competence. Given that our inquiry is quantitative with a large number of participants, we would be faced with the feasibility issue if we were to explore actual recognition. Hence, we adopt Hazari's conceptualization of recognition which refers to perceived instead of actual recognition. In combining these conceptualizations, we adopt the following definitions in this study as four components of a framework for physics identity: (a) competence: actual knowledge and understandings of physics content knowledge, in this case, thermodynamics; (b) interest: desire and curiosity to think about and understand physics; (c) performance: belief in own ability to perform physics-related tasks; and (d) recognition: self-recognition and perceived recognition of how one is recognized by others.

\section{Factors Influencing Identity Development}

Hazari et al. (2010) examined how high school experiences and career expectations influence university students' physics identities through a survey with a large sample of university students $(n=3829)$. The survey included students' demographics, interest, encouragement, and high school physics experiences. The data were analyzed using predictive modeling. The findings revealed a strong link between physics identity and physical science career choice. In terms of the factors that influence physics identities, the following 
were found of importance: conceptual understandings, real-world and contextual connections, the activities of students in answering questions or making comments, students' classmates, and an encouraging teacher. Another important finding related to the component of recognition is the importance of the teachers providing opportunities to students to be recognized by themselves and others as competent physics persons. Building upon these findings, in the study reported in this paper, we focus on the impact of a specific classroom practice on development of physics identities of preservice physics teachers.

\section{Teachers' Positioning}

Another set of studies provided evidence that teachers' positioning has a particular role in identity formation (Hazari et al., 2015; Jackson \& Seiler, 2017). Hazari et al. (2015) reported that teachers' positioning influenced high students' level and types of engagement and the development of their physics identity. In a study examining the differences in students' engagement, including behavioral, affective, and cognitive engagement, and physics identity development, the researchers collected data from four high school physics classrooms. The data consisted of student and teacher surveys, student and teacher interviews, video recordings, and field notes. The analysis of the data showed that students' engagement in classroom activities is influenced by teachers' physical, structural, contextual, and social cues. The teachers' social cues (e.g., showing fallibility, crossing classroom boundaries, and an explicit indication that no one is left behind) appeared to be the most important for affective and cognitive engagement, and subsequently, physics identity development. Meanwhile, contextual cues appeared less prominent, which may indicate the difficulty in making physics content meaningful to the students. Interestingly, even though the findings showed that physical and structural cues appeared to be crucial for behavioral engagement, this engagement was not sufficient for physics identity development. In this study, contextual cues were also embedded in the MR-based instructional approach, especially in the form of building models and situating the physics problems in everyday life contexts.

\section{Programs Supporting Students' Physics Identity Development}

While there is no clear evidence about the types of instructional practices that might support students' physics identity, research situated in out-of-school settings provides examples of impactful activities. Some of the activities that have proven to contribute to students' physics identity development are learning assistant experience (Close et al., 2016), and participation in the Physics Olympiad (Wulff et al., 2011). In a study conducted by Close et al. (2016), the experiences of students in the physics Learning Assistant (LA) program in the USA were analyzed through existing theoretical frameworks of a community of practice and physics identity. The pedagogy component of the LA program includes readings and discussions about constructivism, metacognition, discipline-based education research studies, gender bias, and stereotype threat in science. Research data were collected from teaching reflections, program applications, and interviews with the participants $(n=9)$. Based on the outcomes of the analysis, the researchers concluded that the LA program influenced the participating students in developing both physics students' identity and physics instructor identity.

A study conducted by Lock et al. (2019) explored the impact of out-of-class science and engineering activities on three identity components and the relationship between the components and physics career choice. The activities took place in programmed settings (e.g., 
summer camps and after-school programs), everyday experiences (e.g., reading about science or engaging in science-related hobbies), and designed settings (e.g., visiting museums and zoos). A large survey as part of the project Sustainability and Gender in Engineering was used as a tool for data collection among college students $(n=5541)$. The researchers found that out-of-class science and engineering activities have the largest influence on physics performance/competence beliefs, but the association of performance/ competence beliefs to overall physics identity and physics career choice is primarily mediated through recognition beliefs and physics interests. Moreover, the findings of this study showed that out-of-class science and engineering activities (e.g., participating in science/engineering club, reading science/engineering literature, presenting a science/engineering poster) had a larger effect on recognition beliefs for male students than for female students.

\section{Purpose of the Study}

The findings of the studies reviewed provide evidence that certain types of activities inside and outside the classroom influence students' physics identity. However, what is still missing is an examination of the kinds of instructional practices that might support the development of each of the components of physics identity. We address this gap in the knowledge base through a case study that aimed to examine the effects of an introductory physics course that incorporates the use of MR on the development of preservice physics teachers' four physics identity components. For the purpose of this study, we compared the participants' competence, performance, interest, and recognition before and after the course, and related students' individual perception of the use of MR in the course with these four components. The research questions that guided the study are the following:

1. Does an MR-based instructional approach lead to an increase in preservice physics teachers' actual competence, performance, interest, and recognition as components of physics identity?

2. Does the use of MR predict preservice physics teachers' physics identity components?

\section{Methods}

\section{Research Approach}

We employed a quasi-experimental design to explore the development of participants' physics identities through the use of MR-based instruction in the classroom. The participants were first-year preservice physics teachers at a public university in Indonesia. For the purpose of the study, we investigated if the participants' engagement in an introductory physics course, which incorporates an MR-based instructional approach, leads to changes in their physics identity components. We collected data through pre- and post-tests of physics identity components and students' conceptual understanding, and a post-test on the use of MR. We provide details about the data collection procedures in the following sections. 


\section{Context}

This context of the study was a physics education program at a public university in Indonesia. The physics education program is a four-year program for the preparation of prospective high school physics teachers. Preservice teachers are admitted to the program based on their results on the national university exam and a local test by the university (Faisal and Martin 2019). The first 2 years of this program are focused on physics content knowledge, which covers both classical and modern physics concepts. In the third and fourth years, participants follow methods courses that focus on pedagogical knowledge, such as teaching and learning physics concepts. In the last year of the program, preservice teachers are provided with a teaching practicum in and out of the university. During this activity, preservice teachers apply their physics knowledge for the first time so that they have a chance to gain experience in teaching in the actual situation in high school.

The course which served as the context of the study is compulsory in the first year of the physics education program. Typically, the instructors teach this course with the use of a traditional format with the instructor and the textbook as the main resources of knowledge. The physics topics covered in this course include optics and waves, thermodynamics, and static electricity. Through this course, preservice teachers are expected to understand basic physics concepts and apply these concepts in relevant problems. The participants were 61 first-year preservice teachers, aged 18-19 years from three classes. More than $80 \%$ of the participants were female, which is typical of teacher education programs in the country.

\section{Design of the Intervention}

The introductory physics course was designed based on a problem-based approach that incorporated the use of everyday life examples and MR (i.e., use of pictures, diagrams, equations, and verbal reasoning). As defined by Sutopo \& Waldrip (2014), the MR-based instructional approach refers to a learning process where students are able to construct evidence-based claims, critique claims and representations and then refine both initial claim and representation. A typical lesson structure as part of the course included the following: (a) the instructor provided problems and asked the participants to solve the problems beginning with identifying known variables from the problems; (b) the participants were asked to construct representations such as diagrams, pictures, equations, and verbal descriptions through collaborative work in a group of two or three; (c) the instructor moved around the groups and provided assistance according to written responses of the participants; and (d) the participants shared their work with others through the whole class discussion. The instructor facilitated the discussion to incorporate the participants' responses. The problems used by the instructor were presented with the use of representations in demonstrations, videos of the application of physics in daily life, pictures, and diagrams, in order to build visual models for the participants.

In one of the lessons, the participants had a group discussion and described how they applied concepts of the first of law of thermodynamics using coherent MR. The problem used was about a cyclic process involving some thermodynamics processes as shown in Fig. 1. The instructor guided the participants to solve the problem using representations. First, the participants were asked to identify variables from the problem given a $P V$-diagram of a cyclic process. Then, the participants drew arrows representing the energy transfer as heat or work during each step and constructed verbal descriptions about the process of energy transfer. Following that, the participants were asked to formulate an equation for the temperature of each point on the diagram through the ideal gas equation PV $=n R T$. 


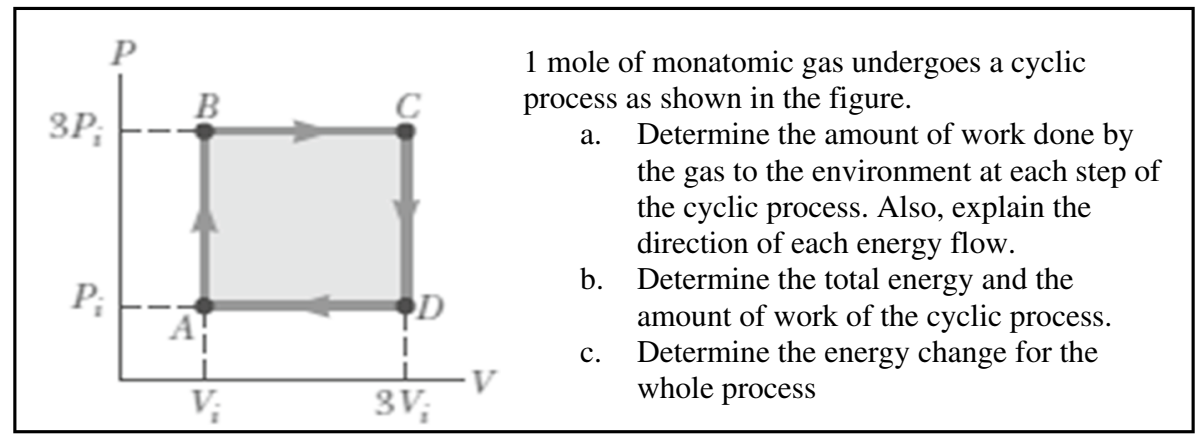

Fig. 1 The example problem: PV diagram of cyclic process (adapted from Serway \& Jewett (2014))

After the participants identified all variables needed such as $W$ and $Q$, they found the relation through the first law of thermodynamics and they described verbally how they had applied the first law. After all the steps and finding the equations for explaining the process, the participants confirmed the result of the mathematical representations, which included symbols, signs, and diagrams. At the end, the participants evaluated all the calculation results and presented their conceptual explanation of the first law of thermodynamics such as "the total change of internal energy of the cyclic process is zero." The participants presented their work in front of the classroom and engaged in whole-classroom discussions. Through this problem-solving process, the participants were supported in developing an understanding of the application of the first thermodynamics law with the use of representations.

These instruction activities were based on the assumption that support of the participants' development of conceptual understanding of thermodynamics would in turn support the development of their competence and performance. A good physics problem solver is able to use the benefits of different representations (De Cock, 2012), and being a good physics problem solver contributes to the expectation of being good in physics (Danielsson, 2014). In addition, activities such as presenting the problems through videos and demonstrations might contribute to the participants' interest in doing physics, which is another component of physics identity.

The intervention was developed by the researchers in collaboration with the instructor and colleagues from the physics department at that university, ensuring that the intervention complies with the expectations and intentions of the instructors. The first author attended and observed all learning sessions to evaluate whether the instructor taught three classes with the same intervention as being planned. In addition, the first author also discussed the implementation of the intervention in the classroom with the instructor who taught the participants. At the time of the study, the instructor had a 10-year experience in teaching with the MR-based instructional approach.

\section{Data Collection}

Data were collected in three phases, as described in Fig. 2. Before the intervention, participants were asked to fill out the physics identity questionnaire that included three components of identity (i.e., interest, performance, recognition) and a pre-test on conceptual understanding. After 4 weeks of instruction with two meetings of $200 \mathrm{~min}$ in each week, the same physics identity questionnaire, the same post-test on conceptual understanding, and a survey on the use of MR 

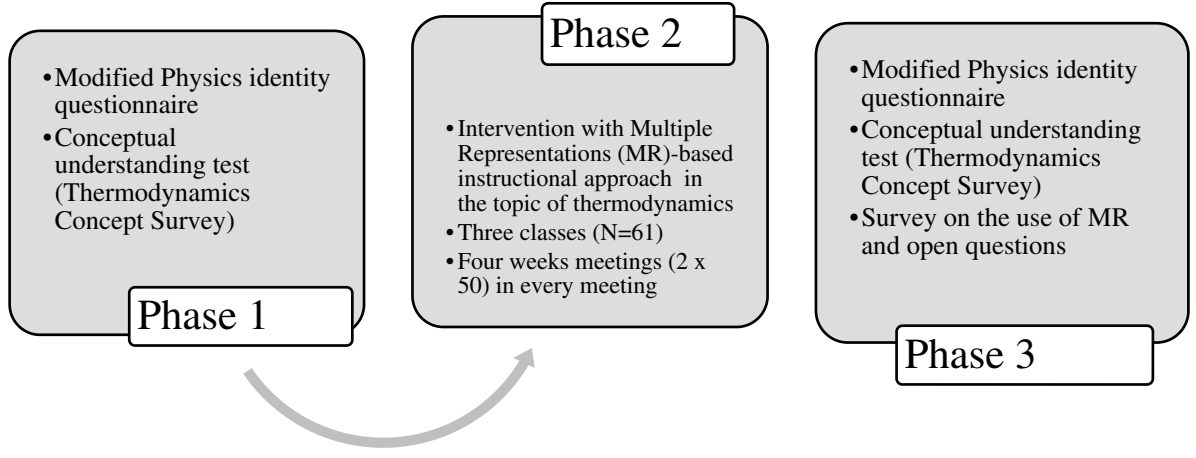

Fig. 2 Research phases and procedures

were administered. The description of each instrument used in this study (i.e., who developed it, for what purpose, and how it was validated) will be explained in the following section.

\section{Instruments}

\section{Modified Physics Identity Questionnaire}

We administered an adapted version of a physics identity questionnaire, originally developed and validated by Hazari et al. (2010) at the beginning and after the learning process to measure the development of three identity components: interest, performance, recognition. We adjusted and translated the original questionnaire and adapted it to the Indonesian context. We selected 18 items of the questionnaire that directly related to the three components of physics identity. To evaluate the content validity of the questionnaire, we discussed the items with a professor in physics education to compare the English and Indonesian versions. The questionnaire items are found in Supplementary Material 1.

\section{Performance}

We collected data on performance with the use of five items which refer to the frequency of individual activities in the classroom such us "teaching the classmates," "getting involved in the small group discussion," and "answering and asking questions." The students indicated their response on a $0-6$ ordinal scale as none (0), very rarely (1), once per month (2), 2-3 times per month (3), once per week (4), 2-3 times per week (5), or every class (6). We found that the value of Cronbach's $\alpha$ for performance was rather unsatisfactory as 0.560 . 


\section{Interest}

In order to measure the development of interest, we used ten items. For example, the items indicated how interesting they find thermodynamics as one of physics topics, and the activities in doing science or physics. The corresponding items were measured on a 6-point Likert scale (1: "not interested at all" to 6: "extremely interested"). The value for Cronbach's $\alpha$ for this component was 0.928.

\section{Recognition}

In order to measure recognition, we used three items on a 6-point Likert scale in the same way as the component of interest. The items in recognition were related to following questions: (a) how do you see yourself as "a physics person"?, (b) how do your parents/relatives /friends see yourself as "a physics person"?, and (c) how does your teacher see yourself as "a physics person"? The participants responded to the items as follows: 1 -no, not at all to 6-yes, very much. The value of Cronbach's $\alpha$ for this component was 0.843 .

\section{Thermodynamics Concept Survey (TCS)}

We used this survey to measure the participants' competence in thermodynamics (actual knowledge and understandings). We adopted the standardized test Thermodynamics Concept Survey (TCS) developed by Wattanakasiwich et al. (2013). We translated this test to Indonesian, and we discussed it with the instructor who taught the course to check the perception and interpretations of the items from the original instrument. The test consisted of 33 multiple-choice items. This test is used as the representation of the participants' actual competence. We found that the value of Cronbach's $\alpha$ for this instrument was unsatisfactory as 0.329 . We presumed this small value was due to cultural differences between the context of the original instrument and the context of this study and the possibility that certain parts of the test were not covered in the course.

\section{Survey of the Use of Multiple Representations}

We adapted the survey of the use of MR from Kohl (2007) to examine the participants' responses regarding their use of representations in solving physics problems, which consisted of twelve items. Some of the survey items refer to the self-assessment of students' performance and competence, and some others focus on the use of representations in learning physics (e.g., I am good at figuring out how closely related different representations are; when I use MR, I do so because it makes problem easier to understand). The participants were asked to rate each item as strongly disagree (1), disagree (2), neutral (3), agree (4), or strongly agree (5). The value of Cronbach's $\alpha$ for this component was 0.827 . We administered this survey at the end of intervention. We also included open-ended questions that aimed to examine if the use of MR influenced the participants' beliefs about their physics ability and interest.

\section{Analysis}

We calculated the mean scores of each physics identity component and conceptual understanding in pre- and post-tests. Next, we performed statistical analyses (paired samples $t$-test) to compare pre- and post-test scores of each of these variables. Based on the normality test using 
skewness and kurtosis, the data for each component of physics identity were normally distributed (Kim, 2013) because the value of absolute $z$-scores for either skewness or kurtosis were $<1.96$. In order to find the correlations of the physics identity components with the use of the MR, we performed regression analysis with the scores of post-tests of each physics identity component as dependent variable and the average of the survey of the use MR as predictor.

\section{Findings}

The findings section is guided by the two research questions with a subdivision based on the four components of physics identity: competence, performance, interest, and recognition. Figure 3 presents an overview of the mean scores of the four physics identity components before and after the intervention. Although some participants had scores lying outside the whiskers of the box plots, such as pre-recognition, post-performance, and postinterest, we included these scores in our analysis.

\section{The Influence of the MR-Based Instructional Approach on Physics Identity Components}

We used the scores of the participants' conceptual understanding test as their actual competence. The maximum score that participants could get is 33 if they answered all the questions correctly. Table 1 presents the mean differences between competence before and after the intervention. We found that there was a significant difference between participants' competence before and after the learning process: paired sample $t$-test $t(61)=6.921$, two-tailed $p \leq 0.001$. The questions that showed the most improvement between pre- and post-test were about the relation between the boiling point of water and its vapor pressure (Q2, pre-test: $28 \%$ and post-test: $72 \%$ correct),

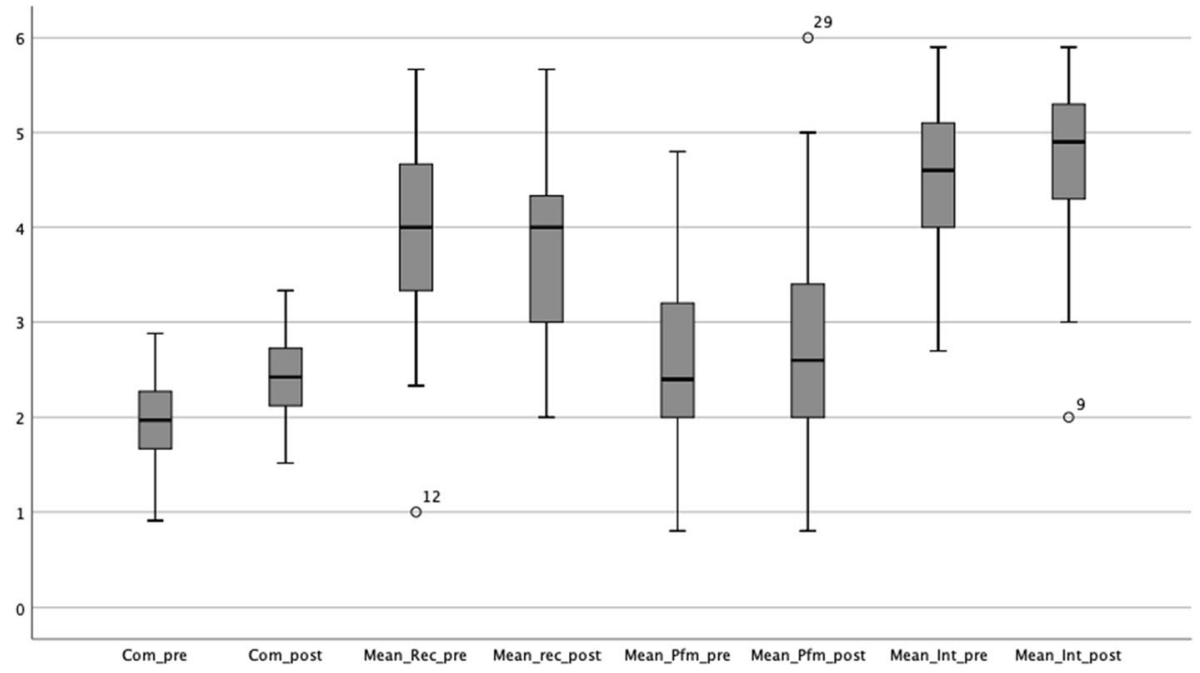

Fig. 3 Box plots with means and standard errors for the components of physics identity in pre-test and posttest 
Table. 1 Mean pre-test and post-test scores and standard deviations (between brackets) of competence, performance, interest, and recognition

\begin{tabular}{lll}
\hline & Pre $M(\mathrm{SD})$ & Post $M(\mathrm{SD})$ \\
\hline Competence & & \\
$\begin{array}{l}\text { The score of conceptual understand- } \\
\text { ing test (Thermodynamics Concept }\end{array}$ & $12.77(2.53)^{*}$ & $15.87(3.14)^{*}$ \\
$\quad$ Survey) & & \\
Performance & $2.55(0.95)$ & $2.75(1.11)$ \\
Interest & $4.52(0.75)^{*}$ & $4.73(0.86)^{*}$ \\
Recognition & $3.91(0.88)$ & $3.77(0.93)$ \\
\hline
\end{tabular}

*significance differences between values of each identity component before and after the learning process

and the pressure of an ideal gas (Q10, pre-test: $20 \%$ and post-test: $56 \%$ correct; Q11, pre-test: $6 \%$ and post-test: $56 \%$ correct). The answers to some questions became worse, namely, on temperature change in an adiabatic process (Q15, pre-test: $36 \%$ and post-test: $21 \%$ correct) and the understanding of heat flow in the thermodynamics process (Q21, pre-test: $41 \%$ and 28\% correct; Q25, pre-test: $28 \%$ and post-test: $15 \%$ correct).

Table 1 also shows the pre- and post-test scores of the other components of physics identity. The difference between the total mean scores of the performance component before and after the instruction was not significant: the paired samples t-test gave $t$ $(61)=1.360$, two-tailed $p=0.179$. For the interest component, we found a significant difference between the total mean scores at the beginning and after the instruction $t$ $(61)=2.653$, two-tailed $p=0.010$. For recognition, the results showed no significant difference between the scores before and after the instruction: paired sample t-test $t$ $(61)=-1.361$, two-tailed $p=0.179$.

\section{The Relationship Between the Use of MR and Physics Identity Components}

Multiple regression analyses were conducted to predict the effect of participants' use of MR on the participants' competence and interest because we only found a significant difference for those two components. The post-test scores were predicted based on the pre-test of those components and the average how the participants used MR through the survey of the use of MR. A significant correlation between students' use of MR and their post-test interest was found $(F(2,58)=36.421, p<0.05)$, with an $R^{2}$ of 0.557 . Participants' predicted post-test interest is equal to $0.190+0.439$ (the use MR) +0.656 (pre-test interest). These results show that the use of MR was positively correlated with participants' post-test interest.

Also, for the competence component, a significant correlation with participants' use of MR was found $(F(2,58)=4,813, p<0.05)$, with $R^{2}$ of 0.142 . Participants' predicted posttest competence is equal to $0.904+0.282$ (the average of the use MR) +0.267 (pre-test competence). However, the pre-test of competence did not significantly predict the score of post-test competence. These results showed that the use of MR correlated positively with participants' post-test competence scores.

To understand how the participants perceived the influence of MR on their physics identities, we used open-ended questions. It was found that the use of MR in the course supported participants in feeling more confident in their ability to learn 
Table. 2 Participants' perceptions of the influence of MR on their physics identities $(N=61)$

\begin{tabular}{lll}
\hline Descriptions & Number participants & Physics identity components \\
\hline $\begin{array}{l}\text { The use of MR can help to understand physics con- } \\
\text { cepts }\end{array}$ & 24 & Competence and performance \\
$\begin{array}{l}\text { The use of MR shows that physics is complex, fun, } \\
\text { challenging, and stimulate to learn more }\end{array}$ & 16 & Interest and recognition \\
$\begin{array}{l}\text { Physics is not only about the use of equations and } \\
\text { mathematics }\end{array}$ & 4 & Competence and performance \\
$\begin{array}{l}\text { Evidence-based and the real-life context are involved } \\
\text { in MR approach }\end{array}$ & 5 & Interest \\
$\begin{array}{l}\text { The use of MR can help the visualization and explain } \\
\text { the simple phenomena }\end{array}$ & 2 & Competence \\
$\begin{array}{l}\text { No explanation, but response that the interest in physics } \\
\text { was increasing }\end{array}$ & 5 & \\
\begin{tabular}{l} 
The interest in physics was not increasing \\
\hline
\end{tabular}
\end{tabular}

physics $(70 \%$ positive responses, $N=43)$. Also, $90 \%$ of participants $(N=55)$ agreed that the use of MR in the course contributes to the development of their interest in learning physics. As described earlier, at the beginning of the classroom instruction, a physics problem was introduced with the use of MR. Following that, the participants constructed other representations of the problem and provide verbal explanations regarding the problem-solving process (Supplementary Material 2). In the end, the participants discussed the problem through a whole-class discussion facilitated by the instructor.

The results of the analysis of the responses to the open-ended questions are summarized in Table 2. We categorized the participants' responses based on the components of physics identity. Some of the participants did not give their explanation. However, some of the participants responded negatively to the use of MR incorporated in the course and made a reference to the difficulties they encountered. They claimed that they did not have sufficient understanding of the basic concepts, and when the instructor used representations, they were faced with more difficulties.

\section{Discussion}

In order to support the development of preservice physics teachers' physics identity development, we implemented an MR-based instructional approach in the context of an introductory physics course. The results of the pre- and post-tests provide evidence that the intervention had a positive impact on the development of the participants' physics identity components.

\section{Competence}

The results of the conceptual understanding test before and after the intervention revealed that there is an improvement of participants' conceptual understanding. Although we did 
not use an experimental design with a control group, the regression analysis showed a correlation between students' use of MR and their post-score results. Therefore, we cautiously argue that the change in participants' competence is influenced by the incorporation of the MR-based instructional approach in this course.

\section{Performance}

The participants' performance scores between pre- and post-test were not significantly different. We expected that participants would have become more active and engaged in the classroom with the MR-based instructional approach. However, we did not find significant differences because participants tended to show less performance in certain tasks as, for example, asking and answering questions. A possible explanation for this might be found within issues related to the cultural context of the study. As argued by Loh and Teo (2017), there is a high power distance between students and the teacher in most Asian countries, including Indonesia. The students are expected to respect the teacher, and they will answer the questions only when the teacher asks them. Thus, communication in the country context tends to be one-way between teachers and students (Loh \& Teo, 2017).

\section{Interest}

Regarding interest, the participants showed a significant difference and a better score after the instructional approach. Even though we cannot draw conclusions because of the lack of a control group, it might be that the instructors' activities, which involved MR such as graphs, pictures, demonstrations and videos, influenced participants' interest. The correlations found between participants' competence scores and their post-test interest seem to point into that direction. These results confirm the findings of the study by Swarat et al. (2012) that the involvement of hands-on activity influences student interest in science. Moreover, the use of real-world problems in the MR-based instructional approach is in agreement with existing literature pointing out that the use of real-world problems can enhance student interest development and engagement (Ainsworth, 1999). The use of digital visualizations, such as video, also seems to enhance students' interest and promote meaning making (Patron et al., 2017). Moreover, understanding science in everyday-life contexts as used in demonstrations and presented in the problems by the instructor can shape students' identities (Hazari et al., 2010). In addition, students' engagement can directly influence their level of interest, thereby reinforcing their physics identities (Stiles-Clarke \& MacLeod, 2018). The consistent use of graphs, pictures, and tables in physics problems by the instructor (Supplementary Material 3) could also be considered as one of the activities that might have enhanced the participants' interest in this study. This supports existing research findings that the use of questions involving graphs and strategies promoting conceptual understanding can positively predict interest as component of physics identity (Lock et al., 2015).

\section{Recognition}

In examining the impact on recognition, we found no significant difference between the pre- and post-test scores. Although recognition can be developed by providing challenging problems for the students and activities for student-centered learning (Hazari \& Cass, 
2018), we realize that this condition may be different for each participant. It is likely that some participants might have experienced difficulties with the MR-based instructional approach. As Maries and Singh (2018) argued, we should be aware of the students' difficulties during the instruction with the MR-based instructional approach, which might provide detrimental effects and lead to the degradation of students' interest. This might explain that recognition was lower after the MR-based practice.

In implementing the MR-based instruction, the instructor tried to direct and scaffold participants in such a way that participants can help one another in solving the problems. These activities might have served as other forms of recognition, according to Hazari and Cass (2018). However, the instructor did not explicitly address special instruction for recognition, such as verbal encouragement, in his teaching practices. This might be another possible explanation of why participants' perceived recognition was not improved.

\section{Participants' Engagement with the Use of MR}

In order to examine how the MR-based instructional approach might support the development of physics identity components we looked into the correlation between the mean scores of the survey on the use of representations and the physics identity components. The regression analysis showed that the post-test scores of competence and interest could be predicted by the participants' self-identification with the use of representations. This finding might suggest that when preservice physics teachers are engaged in using MR to solve problems, this could lead to a positive change of the components of competence and interest. Typically, one of the norms in physics is the expectation of being "good" in physics as being a good physics problem solver (Danielsson, 2014; Due, 2014). Hence, an expert physics problem solver should be able to benefit from using different representations in physics problem-solving (De Cock, 2012).

\section{Conclusions, Limitations, and Implications}

This study provides evidence on how two components of the participants' physics identities might be supported through an MR-based instructional approach in introductory physics. This was evidenced in the changes of two components of physics identity after the participation in the introductory physics course that incorporates the use of MR. The findings of this study also show a positive correlation between self-identification with the use of some representations and competence and interest. From a research perspective, the findings are significant as they contribute to an existing gap in the knowledge base about the kinds of instructional practices that might support physics identity development. For teaching practice and curricular development, the findings provide evidence of the potential that MR-based instructional approaches might hold in supporting preservice physics teachers' development of interest in physics during their first-year of studies, as for example through MR-based curricular that enhance interest in physics and practices that emphasize self-recognition as well as recognition by teachers in the form of feedback.

We acknowledge that the use of the quasi-experimental design in this study cannot definitely answer the question if the intervention causes the changes in physics identity components. Even though the findings show that the intervention is effective in supporting the development of specific physics identity components, we cannot extrapolate about what aspects of 
the instructional practice might have attributed to the change of the components of interest and competence. However, the findings of this study can be used as preliminary evidence that the MR-based instructional approach might support the development of interest and competence.

A follow-up study that uses an experimental design, involving a control group and an experimental group, could provide stronger evidence on the factors that impact physics identity development. Another limitation of the study is that some instruments we used have unsatisfactory value for Cronbach's alpha such as for the performance and competence component. In addition, the sample consisted of a specific group of preservice physics teachers from one university in Indonesia, which even though it is representative in the national context of physics teacher education, the findings cannot be generalized beyond that context.

Summing up, despite the fact that evidence for the use of MR in physics teaching is compelling, the research area at the intersection of MR and physics identity remains largely unexplored. Grounded within the findings of this study, we recommend that future research is directed in this area and specially towards responding to the following questions: What implications does the use of MR hold for physics identity development? What kinds of MR influence physics identity development? How does the context of the learning environment might inform the design of MR-based approaches that aim at supporting physics identity development? What is the role of the instructor in interventions aiming at supporting physics identity development?

Through this study, we provided a specific example of the use of MR as an instructional approach that targets physics identity development in one university classroom. More concrete examples about the use of different kinds of instructional practices targeting the development of physics identity development are needed in order to construct a more comprehensive understanding about the kinds of instructional approaches that might support physics identity development in various learning environments and diverse geographical contexts.

Supplementary Information The online version contains supplementary material available at https://doi. org/10.1007/s11165-021-10019-5.

Open Access This article is licensed under a Creative Commons Attribution 4.0 International License, which permits use, sharing, adaptation, distribution and reproduction in any medium or format, as long as you give appropriate credit to the original author(s) and the source, provide a link to the Creative Commons licence, and indicate if changes were made. The images or other third party material in this article are included in the article's Creative Commons licence, unless indicated otherwise in a credit line to the material. If material is not included in the article's Creative Commons licence and your intended use is not permitted by statutory regulation or exceeds the permitted use, you will need to obtain permission directly from the copyright holder. To view a copy of this licence, visit http://creativecommons.org/licenses/by/4.0/.

\section{References}

Avraamidou, L. (2014). Studies in science education studying science teacher identity: current insights and future research directions. Studies in Science Education, 50(2), 145-179. https://doi.org/10. 1080/03057267.2014.937171

Ainsworth, S. (1999). The functions of multiple representations. Computers and Education, 33(2-3), 131-152. https://doi.org/10.1016/s0360-1315(99)00029-9 
Berge, M., Danielsson, A., \& Lidar, M. (2019). Storylines in the physics teaching content of an upper secondary school classroom. Research in Science \& Technological Education, 38(1), 63-83. https:// doi.org/10.1080/02635143.2019.1593128

Carlone, H. B., \& Johnson, A. (2007). Understanding the science experiences of successful women of color: Science identity as an analytic lens. Journal of Research in Science Teaching, 44(8), 11871218. https://doi.org/10.1002/tea.20237

Close, E. W., Conn, J., \& Close, H. G. (2016). Becoming physics people: Development of integrated physics identity through the Learning Assistant experience. Physical Review Physics Education Research, 12(1), 010109. https://doi.org/10.1103/PhysRevPhysEducRes.12.010109

Danielsson, A. T. (2014). In the physics class: University physics students' enactment of class and gender in the context of laboratory work. Cultural Studies of Science Education, 9(2), 477-494. https:// doi.org/10.1007/s11422-012-9421-3

De Cock, M. (2012). Representation use and strategy choice in physics problem solving. Physical Review Special Topics - Physics Education Research, 8(2), 020117. https://doi.org/10.1103/PhysR evSTPER.8.020117

Due, K. (2014). Who is the competent physics student? A study of students' positions and social interaction in small-group discussions. Cultural Studies of Science Education, 9(2), 441-459. https://doi. org/10.1007/s 11422-012-9441-Z

Faisal, \& Martin, S. N. . (2019). Science education in Indonesia: Past, present, and future. Asia-Pacific Science Education, 5(1), 4. https://doi.org/10.1186/s41029-019-0032-0

Gosling, C. (2017). Identity as a research lens in science and physics education. Journal of Belonging, Identity, Language, and Diversity, 1(1), 62-74.

Hazari, Z., \& Cass, C. (2018). Towards meaningful physics recognition: What does this recognition actually look like? The Physics Teacher, 56(7), 442-446. https://doi.org/10.1119/1.5055325

Hazari, Z., Cass, C., \& Beattie, C. (2015). Obscuring power structures in the physics classroom: Linking teacher positioning, student engagement, and physics identity development. Journal of Research in Science Teaching, 52(6), 735-762. https://doi.org/10.1002/tea.21214

Hazari, Z., Sonnert, G., Sadler, P. M., \& Shanahan, M.-C. (2010). Connecting high school physics experiences, outcome expectations, physics identity, and physics career choice: A gender study. Journal of Research in Science Teaching, 47(8), 978-1003. https://doi.org/10.1002/tea.20363

Irving, P. W., \& Sayre, E. C. (2013). Physics identity development: A snapshot of the stages of development of upper-level physics students. Journal of the Scholarship of Teaching and Learning, 13(4), 68-84.

Irving, P. W., \& Sayre, E. C. (2015). Becoming a physicist: The roles of research, mindsets, and milestones in upper-division student perceptions. Physical Review Special Topics - Physics Education Research, 11(2), 020120. https://doi.org/10.1103/PhysRevSTPER.11.020120

Jackson, P. A., \& Seiler, G. (2017). Identity work in the college science classroom: The cases of two successful latecomers to science. Science Education, 101(5), 716-740. https://doi.org/10.1002/sce.21290

Kane, J. M. (2012). Young African American children constructing academic and disciplinary identities in an urban science classroom. Science Education, 96(3), 457-487. https://doi.org/10.1002/sce.20483

Kim, H.-Y. (2013). Statistical notes for clinical researchers: Assessing normal distribution (2) using skewness and kurtosis. Restorative Dentistry \& Endodontics, 38(1), 52. https://doi.org/10.5395/rde.2013. 38.1 .52

Kohl, P. B. (2007). Towards an understanding of how students use representations in physics problem solving [Doctoral Dissertation, University of Colorado]. https://www.colorado.edu/per/2007/05/01/patkohl-2007-towards-understanding-student-use-representations-physics-problem-solving

Kohl, P. B., \& Finkelstein, N. (2017). Understanding and promoting effective use of representations in physics learning. In D. F. Treagust, R. Duit, \& H. E. Fischer (Eds.), Multiple representations in physics education (pp. 231-254). Springer. https://doi.org/10.1007/978-3-319-58914-5_11

Kohl, P. B., \& Finkelstein, N. D. (2006). Effects of representation on students solving physics problems: A fine-grained characterization. Physical Review Special Topics - Physics Education Research, 2(1), 010106. https://doi.org/10.1103/PhysRevSTPER.2.010106

Lock, R. M., Castillo, J., Hazari, Z., \& Potvin, G. (2015). Determining strategies that predict physics identity:Emphasizing recognition and interest [Paper presentation]. Physics Education Research Conference 2015, College Park, MD,United States. https://www.compadre.org/Repository/document/Serve File.cfm? ID $=13870 \&$ DocID $=4288$

Lock, R. M., Hazari, Z., \& Potvin, G. (2019). Impact of out-of-class science and engineering activities on physics identity and career intentions. Physical Review Physics Education Research, 15(2), 020137. https://doi.org/10.1103/PhysRevPhysEducRes.15.020137 
Loh, C. Y. R., \& Teo, T. C. (2017). Understanding Asian students learning styles, cultural influence and learning strategies. Journal of Education \& Social Policy, 7(1), 194-210.

Maries, A., \& Singh, C. (2018). Case of two electrostatics problems: Can providing a diagram adversely impact introductory physics students' problem solving performance? Physical Review Physics Education Research, 14(1), 10114. https://doi.org/10.1103/PhysRevPhysEducRes.14.010114

McPadden, D., \& Brewe, E. (2017). Impact of the second semester university modeling instruction course on students' representation choices. Physical Review Physics Education Research, 13(2), 020129. https://doi.org/10.1103/PhysRevPhysEducRes.13.020129

Patron, E., Wikman, S., Edfors, I., Johansson-Cederblad, B., \& Linder, C. (2017). Teachers' reasoning: Classroom visual representational practices in the context of introductory chemical bonding. Science Education, 101(6), 887-906. https://doi.org/10.1002/sce.21298

Serway, R. A., \& Jewett, J. W. (2014). Physics for scientists and engineers (9th ed.). Chengage Learning.

Stiles-Clarke, L., \& MacLeod, K. (2018). Demystifying the scaffolding required for first-year physics student retention: Contextualizing content and nurturing physics identity. Canadian Journal of Physics, 96(4), xxix-xxxvi. https://doi.org/10.1139/cjp-2017-0225

Sutopo, \& Waldrip, B. (2014). Impact of a representational approach on students' reasoning and conceptual understanding in learning mechanics. International Journal of Science and Mathematics Education, 12(4), 741-765. https://doi.org/10.1007/s10763-013-9431-y

Swarat, S., Ortony, A., \& Revelle, W. (2012). Activity matters: Understanding student interest in school science. Journal of Research in Science Teaching, 49(4), 515-537. https://doi.org/10.1002/tea.21010

Treagust, D., Won, M., \& McLure, F. (2018). Multiple representations and students' conceptual change in science. In T. G. Amin \& O. Levrini (Eds.), Converging perspectives on conceptual change (1st ed., pp. 121-129). Routledge.

Wang, J., Li, Q., \& Luo, Y. (2020). Physics identity of chinese students before and after gaokao: The effect of high-stake testing. Research in Science Education. https://doi.org/10.1007/s11165-020-09978-y

Wattanakasiwich, P., Taleab, P., Sharma, M. D., \& Johnston, I. D. (2013). Development and implementation of a conceptual survey in thermodynamics. International Journal of Innovation in Science and Mathematics Education, 21(1), 29-53.

Wulff, P., Hazari, Z., Petersen, S., \& Neumann, K. (2011). Engaging young women in physics: An intervention to support young women's physics identity development. Physical Review Physics Education Research, 14(2), 020113. https://doi.org/10.1103/PhysRevPhysEducRes.14.020113

Publisher's Note Springer Nature remains neutral with regard to jurisdictional claims in published maps and institutional affiliations. 